\title{
Design of Practice Teaching for Logistics Engineering Course based on CDIO Concept
}

\author{
Liu Jingyun ${ }^{a^{*}}$, Li Ping ${ }^{b}$ and Geng $\mathrm{Yu}^{\mathrm{c}}$ \\ College of Automation, Beijing Union University, 97 Beisihuan East Road, Chaoyang District, Beijing, \\ China \\ aljy@buu.edu.cn, b'zdhtliping@buu.edu.cn, czdhtgengyu@buu.edu.cn
}

Keywords: Logistics engineering, practice teaching, CDIO.

\begin{abstract}
To meet the increasing requirements of logistics engineers in China, CDIO approach was explored to develop and design the practice teaching of Logistics Engineering course in Beijing Union University. This paper proposed the practice teaching objectives. Then three projects were designed in the Logistics Engineering Laboratory and were introduced in detail. The assessment method of students' performance was also presented which was also developed based on CDIO. This work is supposed to provide a practical teaching solution for qualified engineers' training of Logistics Engineering major and to present a reference for other course development based on CDIO.
\end{abstract}

\section{Introduction}

Logistics is experiencing much faster development in China than ever before and will have a very large market in the following years, which creates the great demand for more qualified application-oriented logistics graduates [1]. Logistics Engineering major is set for engineer cultivation in colleges and universities for the increasingly developing logistics profession in China.

In higher education reform and major construction, the application-oriented graduate education is always one of the most important issues. Massachusetts Institute of Technology (MIT, USA) initiated Conceive, Design, Implement, Operate (CDIO) for engineer training in higher education, which provides an effective methods for engineer cultivation. The objective of the CDIO approach is to train engineers who will be able to solve practical engineering problems, create new products and systems, effectively communicate with society and operate complex systems and programs [2-3]. The CDIO initiative includes a syllabus and 12 principles which provide the abilities that engineers should have and in what way the learning outcomes are assessed.

In China, CDIO approach has been used in colleges and universities since the National Medium-Long-Term Reform and Development Outline for Education in 2010-2020 was released. During the implementation of CDIO-initiative, many achievements have been made and more qualified engineers were trained in different majors. The CDIO approach in education covers training mode, practice teaching, curriculum construction and so on [4-5]. The practice and experience of engineer training in other fields based on CDIO provides references for the Logistics Engineering major. In recent years, the logistics engineer cultivation using CDIO has been explored by some researchers [6-7].

In Beijing Union University (BUU), we have started the study on the engineer education in order to improve the practice and innovation ability of the graduates. Logistics Engineering major was started in 2010 in BUU and the course syllabuses of this major have experienced three-time modification. There is a required course named Logistics Engineering for this major, which is also a very important course for the comprehension of key technologies in logistics. In this course, not only the common logistics engineering technologies and relevant theories are introduced, but also the application projects are included. The application part is organized by practice teaching in laboratory. The Logistics Engineering course has been reorganized based on the CDIO concept, and the practice teaching also has to be redesigned with the CDIO approach. 
This paper is aiming to explore the practice teaching for Logistics Engineering course based on CDIO concept, clarify the teaching objectives, develop projects for practice and improve the student assessment method. The paper is organized as follows. First the practice teaching in Logistics Engineering course was introduced. Then three projects were designed. Lastly, the assessment method was presented.

\section{Practice Teaching of Logistics Engineering Course}

Logistics Engineering course covers the contents such as logistics system analysis, planning, design and optimum distribution of resources, which aims at cultivating students with ability of logistics engineering problem identification and description, modeling and analysis, problem solving and optimization and so on. The practice teaching of this course is supposed to train the student with practical project through which the students will master skills and abilities such as practicing and application of disciplinary knowledge, problem solving, team work, writing and presentation.

We set 6 class hours for the practice teaching in laboratory. Each student have to work in a team with 3 4 students and cooperate with each other. They are required to finish their design report after class. When they hand in their report, a defense is arranged.

The practice teaching of Logistics Engineering course includes three projects which will be introduced in the following part. Each project was organized following the CDIO approach as shown in Tab.1 [8].

Table 1 Organization of practice teaching projects

\begin{tabular}{ll}
\hline CDIO & Contents \\
\hline $\mathrm{C}$ & $\begin{array}{l}\text { Conceive: new ideas and overall perspectives and } \\
\text { problems are identified }\end{array}$ \\
$\mathrm{D}$ & $\begin{array}{l}\text { Design: produce a solution to the problem } \\
\text { I }\end{array}$ \\
& $\begin{array}{l}\text { Implement: structure the project or create the process } \\
\text { Ond realize the solution }\end{array}$ \\
\hline
\end{tabular}

\section{Project Design of the Practice Teaching}

Practice teaching contents cover three projects of which the design is introduced in detail. All the practice is performed in the Logistics Engineering Laboratory as shown in Fig. 1. In this laboratory, logistics facilities and equipments were layout and numbered, including production line, automatic high-rise warehouse system, electronic auxiliary sorting system, computer control console, express delivery system, future supermarket, and office. The present layout is shown in Fig. 2.

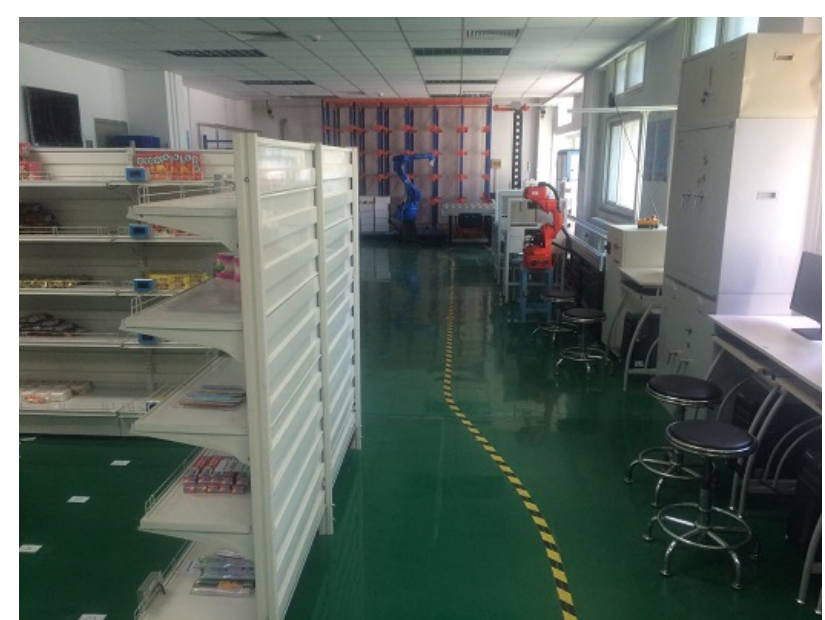

Figure 1 Picture of the Logistics Engineering Laboratory 


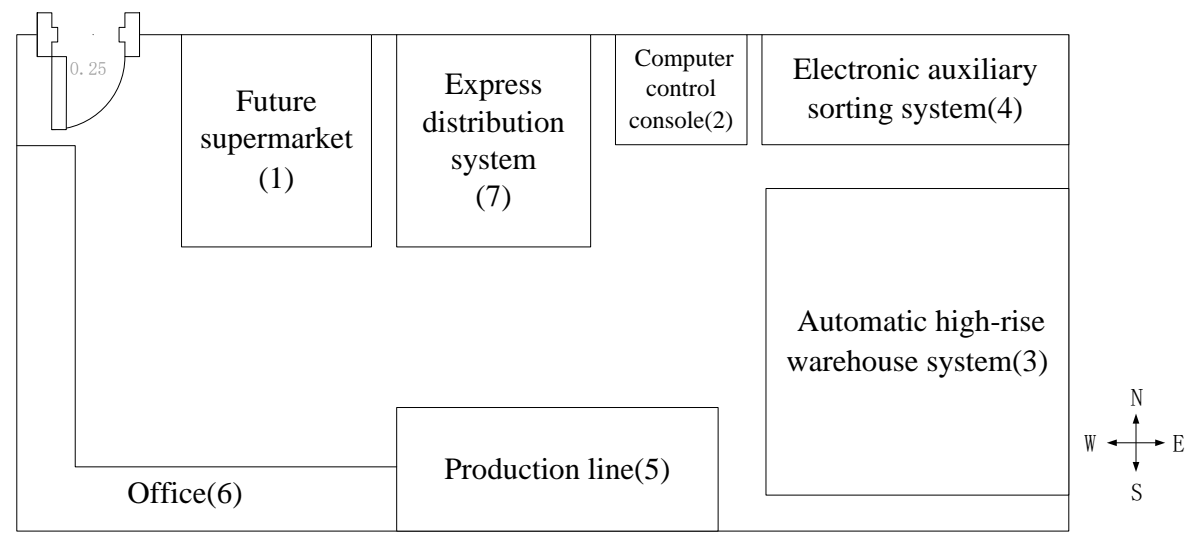

Figure 2 Layout of the logistics facilities and equipment

Project 1. Internet + Express Delivery System Operation. The students are required to learn the intelligent express delivery containers' hardware and software operation, and are asked to perform the delivery process. The containers have boxes of different sizes. The assignment is as follows:

Task 1. Input the delivery bill number and the receiver's phone number through the software interface of the touch panel embedded in the container, and put the package in the appropriate box.

Task 2. The receiver will get his message including the box number and password.

Task 3. The students in charge of the delivery have to monitor the state of the package through the query system.

Task 4. The receiver can also check his package's state and choose to pick it up or not.

Task 5. The receiver has to charge his account in order to pay the express.

Task 6. Finish the delivery.

Task 7. Finish the report and attend the defense.

Project 2. Layout Design Of Enterprise Facilities. This project requires the students to understand the logistics operation process and the relationship between different facilities, analyze the problems in layout design, use SLP or other methods to solve the logistics facilities layout problems. The assignment is as follows:

Task 1. Learn about the present layout of logistics facilities and equipment, and the operation process.

Task 2. Measure the area of each facility and record the data.

Task 3. Analyze the logistics and non-logistics relationship between each facility.

Task 4. Find the present layout problems.

Task 5. Use SLP or other methods to solve the layout problem and draw the new layout picture.

Task 6. Finish the design report and attend the defense.

Project 3. Material Handling System Design. This project requires the students to master how to analyze and solve the material handling problems. SHA method is the suggested solution to the handling problem and the students can used other methods as well. The material handling problems exist in lots of processes among the logistics facilities. There is one given example but it is not limited. The students can also choose other material handling problems in the experimental system through team analysis and solve them. The logistics quantity of the suggested example is shown in Fig. 3. The number above the line means the logistics quantity in ton, and the number of the facilities is the same as in Fig. 2.

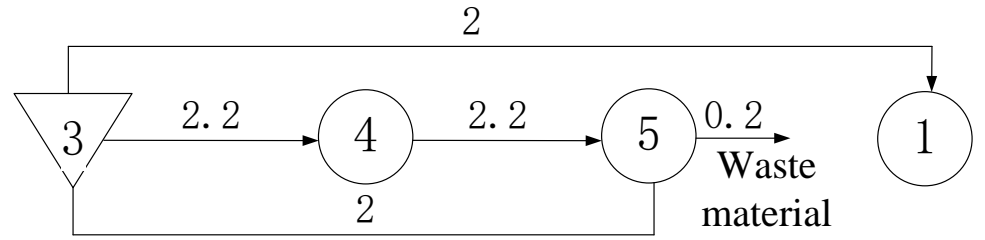

Figure 3 Logistics quantity of the suggested example

The assignment is as follows: 
Task 1. Based on the newly designed facility layout in Project 2, analyze the handling problem according to the logistics quantity between different facilities, including the logistics process, the material type, and handling equipment. A material characteristic table is required to fill in.

Task 2. Draw a table list of handling activities.

Task 3. Draw a logistics map.

Task 4. Analyze the handling plan and make the handling system plan summary table.

Task 5. Finish the design report and attend the defense.

\section{Assessment of the Students’ Performance}

The students' performance during practice teaching is assessed in the process of practice operation, teamwork, design report writing and defense, which is organized based on CDIO. The practice teaching is using centesimal system, which account for $30 \%$ of the daily performance score of the Logistics Engineering course. Organization of the assessment is shown in Tab. 2. There are five parts for assessment and each part account for $20 \%$ of the total practice teaching score. The attendance part is assessed with the students' participation rate during the practice operation, report writing and defense process. The other four parts (CDIO) are assessed with five levels and each level has a range of score which is well designed. With the assessment method, the students' achievement and outcomes are fully evaluated.

Table 2 Assessment organization of practice teaching

\begin{tabular}{lll}
\hline Organization (percentage of total score) & Assessments & Score \\
\hline Attendance (20\%) & Full attendance & 100 \\
Conceive (20\%) & Excellent performance & $90 \sim 100$ \\
Design (20\%) & Good performance & $80 \sim 89$ \\
Implement (20\%) & General performance & $70 \sim 79$ \\
Operate (20\%) & Meet the basic requirement & $60 \sim 69$ \\
& Other & $<60$ \\
\hline
\end{tabular}

\section{Summary}

This paper explored the practice teaching for Logistics Engineering course based on CDIO concept. After clarifying the teaching objectives, three projects for practice were designed in the Logistics Engineering Laboratory. The assessment of students' performance has also been improved based on CDIO. This work aims to improve the students' abilities such as practicing and application of disciplinary knowledge, problem solving, team work, writing and presentation, which will contribute to training of the qualified engineers in Logistics profession.

\section{Acknowledgement}

This work is supported by "2016 Logistics Teaching Reform and Research Project" (JZW2016081).

\section{References}

[1] W.W. Huo, The market demand analysis on china's logistics talent, Log. Eng. Manage., 34 (2012) 7-8.

[2] M. Minin, A. Kriushova, E. Muratova, Assessment of the CDIO Syllabus learning outcomes: from theory to practice, Proceedings of 2015 Int. Conf. on Interact. Coll. Learn., Florence, Italy, Sep. 2015, pp. 689-694.

[3] CDIO Syllabus 2.0, http://www.cdio.org/benefits-cdio/cdiosyllabus/cdio-syllabus-topical-form. 
[4] T. Li, J.L. Qin, X. Zhang, F. Dai, Experiment teaching exploration and practice base on SE-CDIO, Ind. Inform. Technol. Educ.,5 (2015) 54-60.

[5] Y.Z. Qiu, S.J. Li, Y. Xiong, F.F. Liu, Cultivation of application-oriented talent for economic development: teaching practice based on CDIO, J. Shanxi Financ. Econ. Univ., 37 (2015) 98-99.

[6] L.H. Liu, Establishment of the talent cultivation mode for Logistics Management major based on KAQ-CDIO, China Market, 18 (2013) 5-8.

[7] Y.H. Liu, L. F, G. Lin, Establishment of practice teaching system for application-oriented logistics engineering talent education, China Market, 23 (2016) 179-180.

[8] G. Aranguren, J. Ortiz, J.M. Gil-García, From the Idea to the Product: An Academic Tour. IEEE Revista Iberoamericana De Tecnologias Del Aprendizaje, 10 (2015) 291-295. 